\title{
'SlOW' URBAN DEVELOPMENT, THE HISTORY AND THE FUTURE OF POBLENOU, 22. DISTRICT OF Barcelona, Spain
}

\author{
Anna Adorján \\ Department of Garden and Open Space Design, Szent István University, Budapest, Hungary \\ anna_adorjan@yahoo.com
}

\begin{abstract}
Urban renewal projects are based on long-term strategies and huge economical resources. It takes a lot of time to successfully regenerate an abandoned area, create a new centre, infrastructure, businesses, communities. It also needs the kind of systematic and conscious focus that we see in Germany and Scandinavia. While Spain was one of the most touched countries of the economical crisis, it still succeeded at presenting interesting urban development initiatives.

One example is the follow-up of the Olympic development in Barcelona, 22@Barcelona project. I would like to introduce the ongoing project's main objectives and processes and elaborate on the most interesting and valuable results from this project to consider for the present strategy of brownfield renewal in Hungary.
\end{abstract}

Keywords: urban renewal, transformation, industrial area, Spain, 22@Barcelona

\section{INTRODUCTION}

While Barcelona is a vibrant touristic city, it is also the famous economical centre of Catalonia. After the great urban renewal movement before the Olympic Games of 1992, Barcelona suffered from the same tendency as all other European cities: first a sudden and violent growth then the inevitable economic crisis.

The Catalonian capital had enough strength to implement a new, innovative solution and create a new urban model in the name of self-renewal. Moving on to the 1992 model, the 22@ Barcelona Project was created for the renewal of the old industrial areas of Poblenou, the 22th district of the city. [1]

\section{HISTORY}

Poblenou has always been an industrial neighbourhood, with a particular and complex urban fabric and a strong connection to Barcelona due to the railways.22@Barcelona project targets the last transformation of its industrial areas. The area is located north of the Olympic village area and organized by the Diagonal Avenue - business core of Barcelona.

Poblenou played a key role in strengthening the economy of Catalonia as the most important industrial neighbourhood of Barcelona for over hundred years, from the time the first 
Spanish railway was built in the middle of the XIXth century through the area, and it improved its industrial growth. Between 1855 and 1888, the registry of factories recorded an increase from 57 to 243. By the beginning of the 20th Century, San Martín is nicknamed as the "Catalan Manchester" due to its important industrialization and politically active population, and also because of the similar built environment and air pollution.

The most important produce are from the textile sector, the handling of food and wine, metallurgy and construction, without forgetting the agricultural exploitation that always coexisted with industrial use. The plots, factories, warehouses and other industrial buildings have been installed in the structure of the "Plan de Ensanche" by Ildefonso Cerdà.

The mid-1960's brought on the beginning of the de-industrialization of Poblenou. The emergence of the Zona Franca as a new centre of industrial activity in a different, new location inside Barcelona, was a significant blow to Poblenou. Importantly, Poblenou lost more than 1.300 factories between 1963 and 1990. Once the industries started to leave the San Martín district, its neighbourhoods fell into neglect; the factory buildings stood empty and began to degrade. [2].

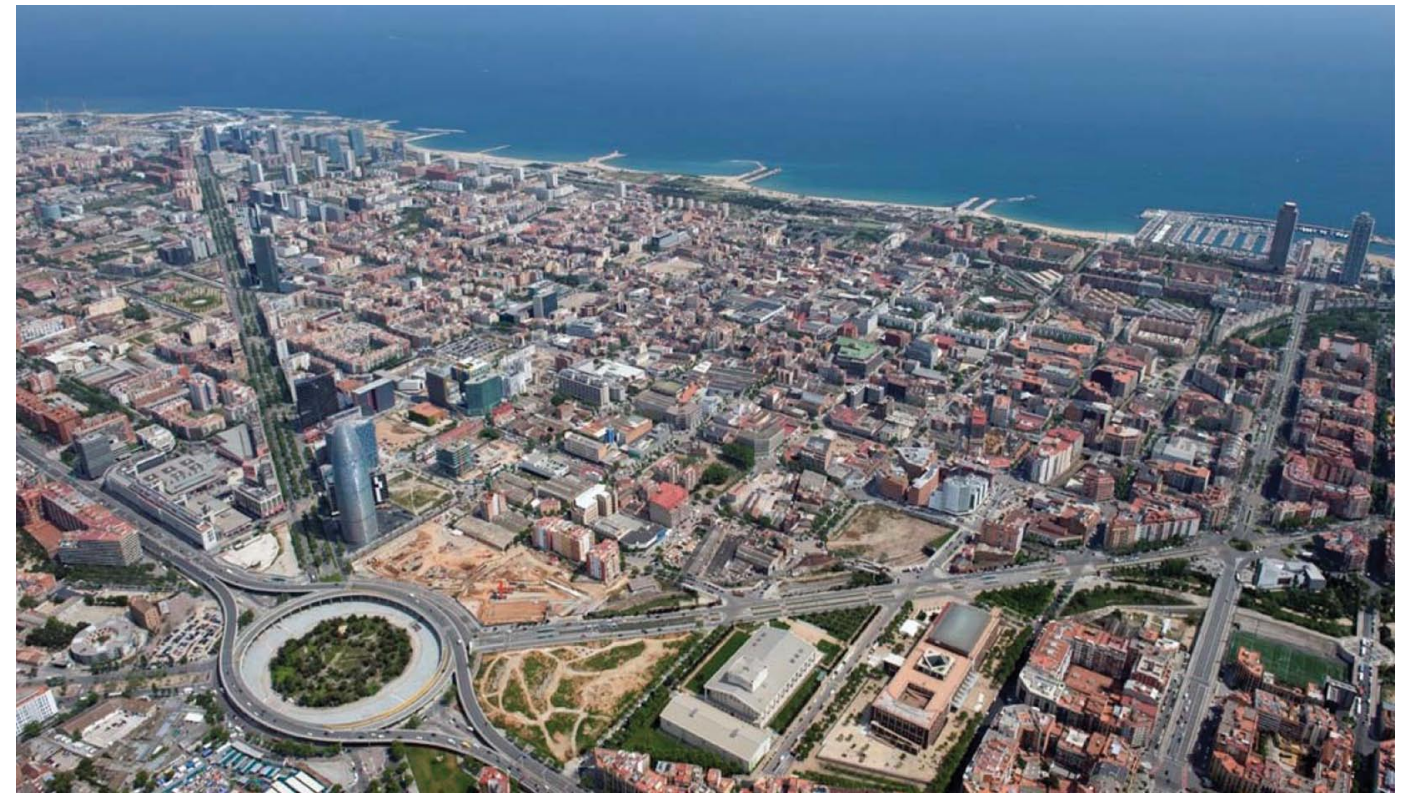

Figure 1. Barcelona, Poblenou area

\section{THE RECOVERY PROCESS}

The recovery of Poblenou is directly linked to the interventions prior to the Olympic Games, for which the ring roads were built in Barcelona, providing Poblenou with an excellent link to the metropolitan area as well as the port and airport; the beaches were turned into urban ground and the Vila Olímpica was built as the first residential neighbourhood on the Barcelona coastline.

In February 1999 the last stretch of the Diagonal Avenue was opened, linking Poblenou to downtown Barcelona. This new perspective triggered an interesting public debate about the future of Poblenou's remaining 200 hectares of industrial land to be refurbished. The discussion ended in July 2000, when all political parties unanimously approved the Amended Metropolitan Master Plan, or 22@b Plan, for the refurbishment of industrial areas of Poblenou. 
The plan itself has many similarities with the rehabilitation plan of IX. district, Budapest. Most important common points are, the strict regulation based on concrete ideas of the future developments (scale, position, function), and the preservation of the existing heritage and valuable buildings.

The renewal started from the main hub, and many acupuncture points inside, and even thought it did not manage to cover the whole area up till now, in the next decade the obsolete industrial areas will be transformed into a space of high urban and environmental quality and with new knowledge-based and innovative investments - according to the 22@barcelona group.

The scale of the project is huge: 198,26 ha, 115 blocks. The area contains 4614 existing dwellings, and the creation of another 4000 new state-subsidized housing units is planned. The strategy envisages the generation of 130.000 new jobs, which may appear to be optimistic but on careful examination it isn't. [3].

What is the key to generating a new metropolitan business and urban metropolitan centre according to the 22@b plan? First of all, the investment of 180 million Euros in public infrastructure development, this creates an attractive investment environment [4]. The attractive ambience includes transport, energy, open-spaces and economical environment. Then the private sector enters, the new start-ups and existing companies also move to and invest in the area and they slowly increase the value and the Poblenou regain its historical, social and economic vitality.

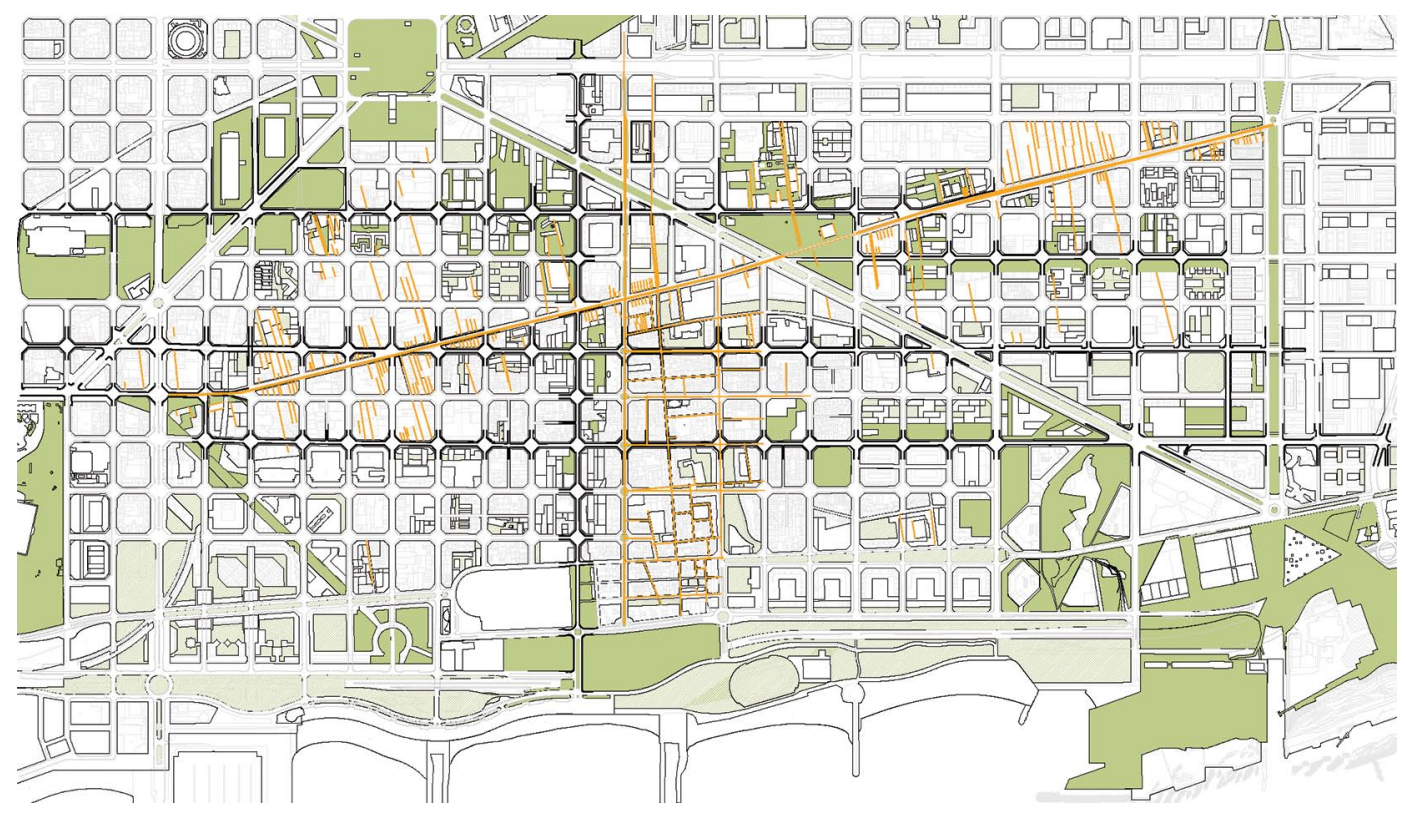

Figure 2. Open-space refurbishments in the Poblenou

One of the main objectives of the project is to reinterpret the function and the spirit of of the old industrial fabric of Poblenou and create a new model of urban space that substitutes the old 22a urban classification. This enables the coexistence of all non-disturbing or non-polluting productive activities, which means a mixed industrial, commercial, residential etc, use. The project and normalizes the presence of the social housing that's been degrading, facilitating its restoration. 
For this reason they plan the area block by block, carefully examining the existent buildings, industrial heritage, residences and operating companies, to create a new model of urban space according to the needs of the current knowledge-based society.

\section{INSTITUNIONAL BACKGROUND}

A municipal society 22 ARROBA BCN, S.A.U., was created in 2000 by Barcelona City Council with the aim to promote and manage the planned transformation for 22@Barcelona project. The organizational structure of the company is in three level: the experts of the Urbanism, Management and Infrastructure Directorate are controlled by a Head of project manager, and the whole organisation is under the control of an Administration Committee.

The Directorates have their own responsibilities based on their expertise: coordinate the infrastructural developments, urban projects and manage the ongoing development projects in the neighbourhood. The team of the Management Directorate runs the actual promoting events and also works to build and maintain the network of entrepreneurs, developers and expert to create a local business community. It is also determined to promote the institution and development of strategic contents in these newly created spaces facilitating the international projection of the new business (like media clusters and ITC-s), scientific (9 centers of R \& D and technology transfer), education (10 universities) and cultural activities (Design Museum) of the area. [5]. In the last 15 years it operates and maintains the interest in the project. [2].

\section{GOALS AND RESULTS}

Since the beginning of the project the refurbishment of $70 \%$ of the area began, under 139 plans for urban amelioration. Said projects will result in obtaining over 3,029,106 $\mathrm{m}^{2}$ for new production facilities, social housing, facilities and technical services.

The real estate sector has decisively supported the Project: 84 of the 139 plans approved are promoted by the private sector, of which planning permission has been granted to build $691,291 \mathrm{~m}^{2}$ of over ground GFS for production activities.

The 22@Barcelona project likewise was warmly received by the business community: an estimated 4,500 new companies have moved to the district since 2000, although the most prolific era was from 2003 to 2006 . Of the 4,500 companies, $47.3 \%$ are new start-ups, the rest have moved from other locations because of the effective promotion and good financial opportunity. $31 \%$ of them are technological or knowledge-based companies.

As a result, the number of people working in Poblenou has risen significantly, and the area is on the way to his new life. There are currently more than 56,000 new workers, half of them with university degrees, and that number is predicted to reach 150,000 if the existing holes and unfinished developments are completed. [2].

\section{REFLECTIONS}

According to Joan Busquets [5] Barcelona has been subject to many urban changes since 1933, which can be divided in three blocks:

-Redefinition of the road system

-The culmination of some areas of new centrality

-New large urban axes 
The second and the third block includes the transformation of the Eastern Barcelona, such as the extension of the airport, the public transport plan and the AVE network, and also include the creation of the Universal Forum of Cultures of 2004. Together with this investments comes the 22@ Project, which is therefore a part of a bigger renovation of the city.

The Poblenou project main structural investment is based on the layout designed by Cerdà, who wanted to connect Glories to the Sea. This project can convert Glories into the new urban hub, something which was desired by Ildefons Cerdà.

The projects - especially these from the late nineties - implement the idea of renewing the city into the new industrial, economical and social context, have proved Barcelona's capability to transform and adapt to new economies, with a new definition of space that could strengthen its position among other European cities.

Focusing mostly to the architectural image due to urban changes, we can say, that during the last decades Barcelona has reached a central status on the European scene, and with all these projects its image also changed. The emergence of new architectonic icons can make Barcelona not to be regarded anymore as a modernist city having the "Sagrada Familia" as the main identifying building, but to be remembered and identified with a new Skyline of Barcelona which includes the buildings from the 22@project [7].

Even though the architectural image is an important aspect, only with the iconic new buildings a city can't facilitate his economic grow and urban renewal. The other several aspects, such as individual residents and community of a neighbourhood are also need to be considered

Analyzing the community based, private sector involved renewals, Philip Speranza makes an argument for a bottom-up approach to urban planning and highlights long-term advantages of fostering "the myth of the pueblo" [8].

To make a contrast between the bottom-up placemaking case studies in and around Barcelona (such as Gràcia and 22@) and the top-down regional planning initiatives (Olympic Village and 2004 Forum of Cultures), Speranza collets the features of local identity and social behaviours that give Barcelona its local city identity and reflect the myth of the pueblo:

- Festivals

- Public food markets

- Non-traditional lunchtime eating habits

- Playground spaces

- Beachfront recreation

- Limited vehicular traffic

- Space calibrated to pedestrian scale

- Winding streets

- Numerous public plazas

- A spatial and social sense of smallness

- Low cost rental for artists, designers, and artisans

These are mostly found in the Gracia and 22@ and in many other successful community based renewal projects.

On the other hand the factors that contributed to the lack of local neighbourhood identity for the Olympic Village development and 2004 Forum of Cultures (which is the most unsuccessful project in Barcelona according to professionals):

- "Superblocks"

- American-type enclosed shopping mall

- Generic urban features 
- Loss of working class character

- Demolished the majority of the historical architecture

- International architects

- Valuing city marketing and real estate development over needs of local citizens

This is a remarkable and also obvious couple of examples, which are constantly made when the topic pop up, and the tools are also well-known but a collection like this helps to understand the successful progress better.

\section{CONCLUSION}

The history of the area is similar to many Hungarian examples, the presence of the railway, intense industrial developments, pollution and the lack of a healthy living environment in a greatly popular neighborhood.

The renewal strategy is not unique but summarizes numerous existing tools and allows the monitoring and a periodic synchronisation of the actual needs for better result.

If we go into detail, I agree with what Speranza said about the most important lessons of the projects:

- The adaptation of new information to gather activities into existing fabric of the community infrastructure

- The block-by-block approach helps to limit the private developers, and on the other hand makes the project more personalized

- More open space/publicly accessible space (according to Speranza 10\% minimum) is needed to avoid the superblock effect and increase ground floor activities

- Protect existing built fabric, industrial heritage and urban structure (Cerdà plan)

- Open-ended flexible design

Budapest has similarities with Barcelona: the waterfronts in the outer areas of the city- especially the riverside of the Danube has been used for industrial sites, and in the IX. and XIII. district the railways improved the industrial developments in the 20 . century - just like in Poblenou. There is also valuable industrial heritage building stock, and the private sector based brownfield renewal program of the capital is ongoing, so it is extremely important to learn from the 22@ model.

In the Hungarian context, we should also mention that a constant, persistent and active institutional background is needed. It is also essential to maintain the interest of the political and private sector for the decades of the renewal. 


\section{REFERENCES}

[1] NeL·LO, Oriol “The Olympic Games as a tool for urban renewal: the experience of Barcelona'92 Olympic Village”, in „Olympic Villages: a hundred years of urban planning and shared experiences” compiling the papers given at the 1997 International Symposium on International Chair in Olympism (IOCUAB)

[2] 22@Barcelona: 10 Years of Urban Renewal. 2010 Barcelona, Ajutament de Barcelona. 30. http://www.22barcelona.com/

[3] Clusa, Joaquim 1996 „Barcelona: Economic development 1970-1995” in HARRIS, Nigel and FABRICIUS, Ida, Cities and Structural Adjustments. London : University College of London Press, p.203-237.

[4] La Modificación del Plan General Metropolitano (MPGM), Barcelona 2000,

Ajutament de Barcelona

[5] http://www.morethangreen.es/22barcelona-the-innovation-district-el-distrito-de-la-innovacion/ Ivan Capdevila, 2012.04.1.

[6] Busquets, JoAn “Barcelona, a European city. Another change of scale?" in Barcelona: the urban evolution of a compact city, Harvard University, Graduate School of Design: 2005,p.424

[7] https://communitydrivenurbandesign.wordpress.com/2013/03/09/reflections-on-catalan-nation-building-and-bottom up-placemaking/

[8] Speranza, Philip “ Catalan Nation Building and Bottom-Up Placemaking and Barcelona Coastal Redevelopmentin the 22@.” International Association for the Study of Traditional Environments, The Myth of Tradition, Volume 242, 2013. Traditional Dwellings and Settlements Working Paper Series, Berkeley: IAESTE

Figure 1. Barcelona, Poblenou area, source: 22@Barcelona: 10 Years of Urban Renewal. 2010 Barcelona, Ajutament de Barcelona. 30. http://www.22barcelona.com/

Figure 2. Open-space refurbishments in the Poblenou ,source La Modificación del Plan General Metropolitano (MPGM), Barcelona 2000, Ajutament de Barcelona 